Byung-In Seo

Chicago State

University, U.S.A.

DOI: http://dx.doi. org/10.18820/2519593X/

pie.v37i2.10

ISSN 0258-2236

e-ISSN 2519-593X

Perspectives in Education

2019 37(2): 141-159

Date Published:

27 November 2019

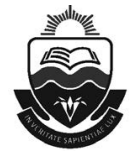

Published by the UFS

http://journals.ufs.ac.za/index.php/pie

(9) Creative Commons

With Attribution (CC-BY)

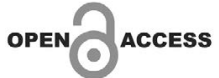

\section{AN INVESTIGATION OF HOW 7TH GRADE AND 8TH GRADE STUDENTS MANIPULATE MATHEMATICAL WRITING ELEMENTS}

\begin{abstract}
All mathematics is comprised of three elements: symbols, nominalizations, and images, and the combination of these three elements determine the mathematical meaning. However, adolescents may not be aware of these three elements. When asked to describe mathematical language, they will often name equations and images, two of the three elements. Over the course of six months, 1,276 mathematical writing samples were gathered from 7 th and 8th grade students. The research question of this study is: What mathematical writing elements are 7th and 8th students using in their mathematics classes? This paper describes a preliminary analysis of a larger data set of adolescent mathematical writing. Preliminary analysis focused on 7th grade and 8th grade students' uses of mathematical writing elements during their routine instruction, and the data showed that these students used the mathematical element that was asked of them by their teacher. These kinds of responses showed that students employed audience theory, Audience theory is when the writer is cognizant of his/her reader and will adapt the written work to that specific reader. In this case, the students mathematically wrote in a way that was expected by the teacher. When the teachers gave mathematical problems within a specific framework or graphic organizer, students complied with that format, using the appropriate mathematical element. Both groups followed the directives of their teachers, using the mathematical elements that were asked of them.
\end{abstract}

Key words: Mathematical writing; Adolescents; Writing elements; Context; Form

\section{BACKGROUND OF THE STUDY}

In 2000, the National Council of Teachers of Mathematics (NCTM) in the United States wrote mathematical principles and standards that students should know at each grade level, and for the first time, NCTM adopted Communication Standards for all grades. These standards focus on not only mathematical knowledge but also how that knowledge is conveyed in written and oral forms. Their goal is to improve mathematical knowledge and application for all students. When these standards were adopted, the focus was on the use of conventional words in explaining mathematical thinking, for students to clearly express their mathematical 
ideas and thinking processes to not only their teachers but also to people outside of the mathematics classroom, like their friends and family members.

Since these standards were adopted, the majority of the research in the United States on adolescent mathematical writing has focused on this communication standard. Writing became a means of understanding the students' thinking processes by improving the communication between the students and their teachers. For example, incorporating journal writing in the students' routine instruction has allowed students a means of expressing their mathematical attitudes, confusion, and anxieties. Students who normally would not speak up in class were more communicative in written conversations (Baxter, Woodward, \& Olson, 2005; Mclntosh \& Draper, 2001; Pugalee, 2001; Williams, 2003). More recently, Bruun, Diaz, and Dykes (2015), Martin (2015), Colonnese, Amspaugh, LeMay, Evans, and Field (2018), Jao and Hall (2018), focused their research on how students communicate mathematical concepts using scripted words. Brozo and Crain (2018) gives instructional strategies on how students can express mathematical symbolic notation into scripted words. While Santos and Semana (2014) included mathematical symbols and images as part of student writing, their emphasis with regards to assessment was on the scripted words.

Studies have shown that writing helps with the metacognitive processes of learning mathematics (Bruun et al., 2015; Colonnese et al., 2018). Therefore, students' mathematical writing primarily is reflective and used at a personal level. Beyond the personal level, mathematics teachers understand that when students communicate a mathematical idea clearly to another individual, then the likelihood of that student understanding the mathematical concepts are high (Brozo \& Crain, 2018; Jao \& Hall, 2018). When reading a mathematical text, the author uses different mathematical writing elements, but current research focuses on the students' uses of either scripted words (text) only nor symbols and text. The research problem focuses on the need to improve students' mathematical communication beyond focusing on the students' uses of scripted words. However, before any improvements can be made, it is necessary to understand the kinds of mathematical writing that students produce in their mathematics class.

\section{AIM OF THE RESEARCH}

Mathematical communication needs to improve. In the United States, NCTM (2000) determined clear communication guidelines because they saw a need that students need to not only know procedural mathematical knowledge but also be able to convey this knowledge to different kinds of audiences. Teachers of mathematics must give their students opportunities to "think through problems; formulate explanations; try out new vocabulary; experiment with forms of argumentation;' justify conjectures; and reflect on their own understanding and on the ideas of others" (p. 272). As one can see, the focus is on the words students need to use, while the incorporation of mathematical notation is implied. However, there needs to be equal analysis of all aspects of writing in mathematics class to include symbols, nominalizations, and images. The current emphasis on analyzing scripted words disregards other aspects of mathematical writing. Once this understanding has been established, then there can be a discussion about curricular and instructional changes. Therefore, this paper focuses on one aspect of the collected data, how pre-secondary level students use the mathematical elements in their routine instructional lessons. The research question is: What mathematical writing elements are 7 th and 8 th grade students using in their mathematics classes? 
Even though this study was completed in the United States, findings can be applied to South African students. American and South African students cover the similar topics at the same grade levels. Similar to the United States, South Africa also wants to improve mathematical abilities, and communication is one of those abilities. With the exclusion of one or more of the writing elements, these elements are either disregarded or forgotten. For example, in the Grade 10 Everything Maths textbook (Kannemeyer, Jenkin, van Zyl, \& Scheffler, 2014), the focus is on equations and calculations. The images are used as organizational tools for clarification of the equations. This book has no lessons on the use of nominalizations, highly specialized text that is uniquely mathematical. The reality is that there needs to be an understanding of how students use all three elements as communication tools. Therefore, there is a great likelihood that both sets of students may use similar mathematical writing elements but have not been investigated.

\section{THEORETICAL FRAMEWORK}

The theoretical framework for this study focuses on different perspectives of mathematical writing. Morgan (1998) had earlier stated that there was no true definition of mathematical writing because mathematical writing can be seen in many forms. Mathematical writing is multi-dimensional (Ernest, 2008a, 2008b; Seo, 2009). However, mathematical writing is no different from other genres, in that all writing is comprised of elements, and those elements are part of its discourse (Gee, 2015). The conventional definition of "writing" primarily focuses on linguistic features of writing, the syntax, lexicon, and diction. Mathematical writing has these linguistic features, but the elements of this kind of writing are different; they are subject specific. Lemke (1995) describes scientific and mathematical languages to be highly condensed. Condensation is taking a complex idea and condensing it into a few words or symbols. For example, in pre-secondary level mathematics, students may learn the concept of "slope." While the basic definition of "slope" is "rise over run," a sentence "slope $=1 / 2$ " conveys more than the "rise over run." It conveys the direction, the steepness, and its X- and Y-intercepts. In this study of mathematical writing, it is specifically comprised of three basic elements: Symbols, nominalizations, and images (Seo, 2015).

\subsection{Symbols}

Symbols are any mark on a surface that convey meaning, and that meaning changes according to context (Harris, 1995; Rotman, 2000). For example, "- " is just a horizontal line. However, when it is typed as "mixed-methods," it is a hyphen. While in this context, " $5-2$," it denotes subtraction. Keep in mind that it is the same horizontal line, only its context changed. Symbols are the essence of mathematics. Its combination provides the mathematical language used in its understanding (Sfard, 2000). Symbols delegate complex cognitive tasks to an external environment (van Dyck \& Heefer, 2014). Mathematics can be seen as a transposition of symbols. Even though the format of the equations change, as each process is carried out, it is essentially the same as the previous equation. The equations may look differently, but the meanings are similar. The way students use symbols is a product of their environment. Teachers model the "correct" way to use the symbols, and the students will emulate it in order to get a positive grade from the teacher.

Mathematics is a field of condensation where there are multiple meanings and functions within one notation (O'Halloran, 2008). There are different kinds of symbols. Numbers and letters are commonly recognized, and their combination shows a condensation of meanings 
and activity. For example, in order the understand " $3 x$," one needs to first understand that " $x$ " denotes an unknown number, and this unknown number can be of any value. Also, the combination of the " 3 " and the " $x$ " next to each other shows that they are being multiplied together. The multiplication sign is omitted, because there is an understanding of the multiplicative action that is taking place in this combination. [ ] and ( ) designate the order of operations within an equation. [(3-1) + (4-3)] means that the actions within the parentheses needs to be completed first. Then, the answers from within the parentheses are added, to have a final product. Mathematics can be seen as a transposition of symbols, where even though the format of the equations change, as each process is carried out, it is essentially the same as the previous equation. The equations may look differently, but the meanings are similar. The way students express their mathematical thinking changes as their audience changes. For example, Seo $(2009,2011)$ learned that when adolescents were given mathematical prompts in both English and mathematics classes, even though the students wrote the same meanings, but their writing changed. Writing from the mathematics classes only contained symbols in the form of equations, while the writing from the English classes contained scripted words (nominalizations) along with the symbols and equations.

Logograms are symbols that represents an idea. Logograms, are also referred to as ideograms, even though there may not be a direct association to speech or a phonetic sound (Harris, 1995). Examples of ideograms are Chinese characters and Egyptian hieroglyphics. In both of those example, one character or one picture represents an idea. In mathematics, logograms are primarily used to represent an action or activity in the problem. For example, "+" means to add together two or more items. "=" isn't a number or a letter, but it is still a symbol. Other symbols are "-", "\%" and "=". All of these symbols show some kinds of action or activity that needs to take place, but there is not a specific phonological identity to them. In order for the activity to take place, the student needs to understand the meanings of the logograms. In general, logograms don't change their meanings as their context changes. "+" is still addition no matter where it may be placed in the text, and "\%" still means percentage.

There are mathematical symbols whose role is to keep order of the operations. Brackets and parentheses are used specifically to provide order in the operations. If there are mathematical activities within parentheses and within brackets, the activity within the parentheses are always calculated first. Then, once those calculations have been completed, then the calculations within the brackets are completed. It there are multiple parentheses and brackets, the calculations are completed inside-out (O'Halloran, 2008). In Figure 1, this 7 th grade student used parenthesis to group the additive numbers prior to distributing the multiplicative value:

The way mathematical symbols are written follow a certain format. With scripted words, that writing is linear. In English, the words are written and read from left to right. In mathematics, while each step it written and read left to right, the steps are written vertically, as in Figure 1. This vertical structure adds to the condensation of the mathematical meaning. The writing is easier to read and discern when written vertically. Each step is a line unto itself, and the logical order between steps is evident. If these equations were written in paragraph form, there would be a need for transitional words, linking one step to the next. In its vertical format, the transitions are assumed, since one step follows the other. 


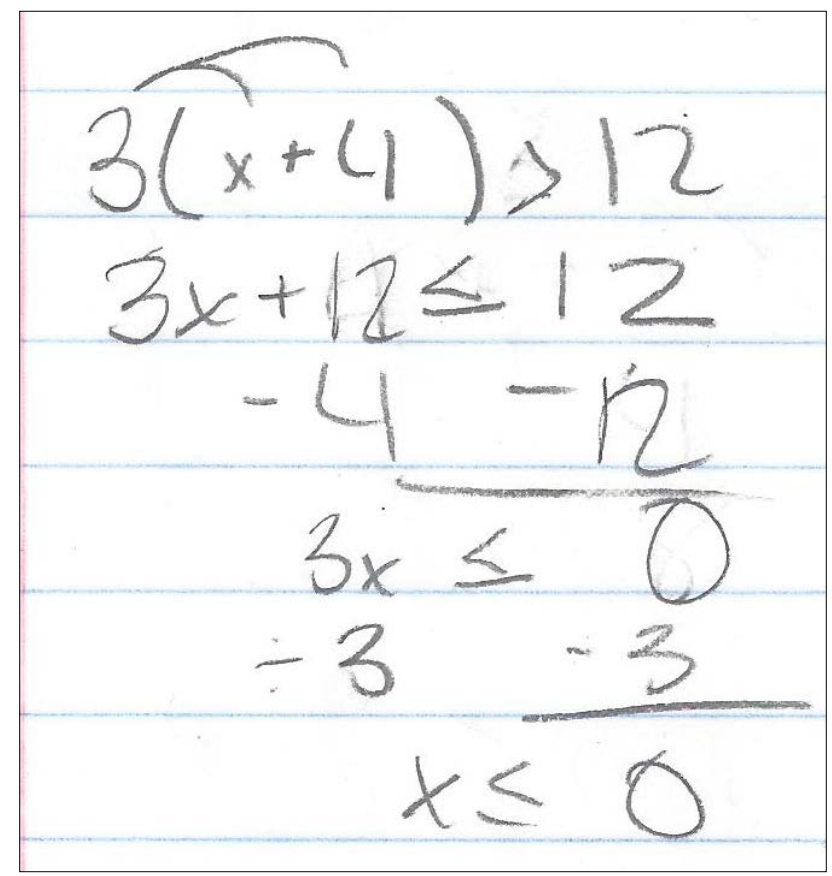

Figure 1: Vertical manifestation of mathematical processes from a 7 th grade student

Symbolic writing can be seen as variations on a theme. In Figure 1, the initial equation and its answers are the same values. While the used of symbols differ, the meaning stays the same. One is the numeric figure. Second is multiplication. Third is subtraction, and fourth is division. In this case, each process depicts a different meaning, showing how the different combination of symbols, while the same, can also be quite different. Nevertheless, there is an assumption that the reader understands each of the symbolic combinations in order to discern that the meanings are the same (Danielson, 2010).

Figure 1 shows how mathematics is condensed from an equation to a single value. Mathematics is reliant on writing and its symbols. Without them, the realm of mathematics would be limited because everything would need to be thought based. With writing, people can visually represent their mathematical meaning and visually show how the meanings can be manipulated to either produce new meaning or show that the meaning stayed the same. Mathematical semiotics is "unambiguously encoded in ways which involve maximal economy and condensation" [author emphasis] (O'Halloran, 2008, p. 97). The economical encoding allows the symbols and mathematical functions to be manipulated in a way that different orders and placements still allows the mathematical problem to be solved and the meanings to emerge. Items in the inner brackets in Figure 1 can be rearranged, and the meanings would stay the same. For example, $(x+4)$ can be written as $(4+x)$, and the meaning would stay the same. It is necessary to examine students' uses of symbols because symbols are the most commonly used mathematical writing element at these grade levels. 


\subsection{Nominalizations}

Nominalizations are highly condensed acronyms, words, and phrases to explain a more complex idea. It is a type of thematic condensation (Lemke, 1995). These meaning-packed words are nominalizations. The term "nominalization" is when an activity including its participants and circumstances is put into a noun form. Once in this form, the noun is used instead of describing the whole activity and/or explaining the complete process. It is seen as the shortest or easiest way to describe an action or concept. For each genre, the specific knowledge, processes and context need to be specified, in order for the nominalization to be understood (van Dijk, 2008). Thematic condensation works because there is a tacit agreement on the meanings of the words. This nominalization process an example of thematic condensation, where the implied activity can be qualified and related to other activities in a condensed manner. Mathematics by its nature is condensed, and the economical use of symbols shows the greatest amount of meaning in as few "words" as possible (O'Halloran, 2008). In 8th grade, students are taught the concept of "slope." Slope is the gradation of a line on a Cartesian graph, determining its steepness and direction. Commonly known as "rise over run," 8th grade students are often not aware of its multiple meanings. When asked, "What is the slope of this line?" students need to not only explain how steep it is but also its direction and where it intersects the X-and Y-axis. Another nominalization is "Distributive Property." In mathematics, this property stated that with a group of numbers, one would get the same answer whether a number is multiplied to the whole group or whether that number is multiplied to each individual number in the group and then add them together. In both cases, students may be able to complete the procedures without understanding that these terms represent a more complex meaning. By understanding the different nominalizations that these pre-secondary level student use, teachers can obtain a better idea of their students' mathematical communication abilities.

\subsection{Images}

Images are anything that is not a symbol or a nominalization (O'Halloran, 2008). They can range from diagrams, organizational tools (i.e. T-chart for geometric proofs), to tables and graphs. Similar to nominalizations, images can be highly condensed, using one image to convey multiple concepts. These elements can represent mathematical ideas in succinct ways. Diagrams represent the mathematics within a problem without specific surface details, and pictures can be used as placeholders of thought (Pimm 1995). In addition, unlike symbols, images are static. For example, Figure 2 has an image from a 7 th grade student:

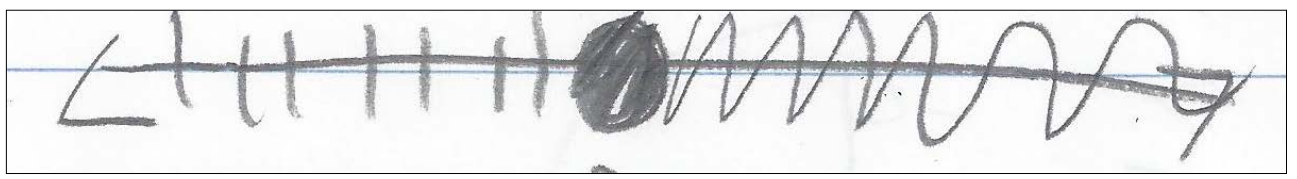

Figure 2: Image from a 7th grade student

In this image, it is clear that it is a number line. There is a designation of " 0 " in the middle of the line, and there are vertical lines to the left of the " 0 ", to designate negative numbers. In addition, there is a squiggly line to the right, designating that the line represents " 0 " and all positive numbers. As seen in Figure 2, images can convey multiple meanings. When combined, these multiple meanings can give an overall significance to the image, similar to a paragraph (Rotman, 2000). As previously stated, mathematics, by its nature, is a form of 
writing that is compact and impactful. Images are one kind of compaction. It is necessary to understand students' uses of this mathematical element in order to fully comprehend their mathematical concepts and ideations.

\subsection{Negotiation of Elements}

One of the difficulties of learning mathematics is the negotiation of these three elements to convey meaning. Mathematics is primarily a written language as opposed to a spoken one. Mathematical discourse and condensation promotes a kind of elitism (Lemke, 1995). For example, when stating "SSS Inequality," mathematicians can identify the postulate. It represents only one postulate, no others. Individual symbols may be easier to understand, but when groups into Nominalizations and other condensed vocabulary have determined meanings, and those meanings are agreed upon within the member of "the club." Any opposition to these meanings is not tolerated. Similar to other non-native languages, mathematical and scientific language tends to be exclusive. Those people who are not able to negotiate these three elements fluently will not be able to communicate to others in this field.

There are difficulties in traditional writing analysis in mathematics. Traditional analysis focuses on scripted words. In mathematics, "words" needs to be defined. If "words" are a combination of symbols that have a specific meaning (Harris, 1995), then "SSS" and " 3 " would be considered words. However, if the definition of "words" means that they need to have morphemes, then two-thirds of the mathematical aspects would not qualify.

Three aspects work simultaneously: symbols, nominalizations (which includes scripted words), and images. All three aspects are needed in order to understand the full mathematical meaning. Without one of them, the meaning would be incomplete (Hammill, 2010). Students write what they see and what they expect from their teachers. As a result, students primarily learn how to manipulate these elements based on what they are taught. Based on informal interviews with three high-school mathematics teachers, the focus of high-school mathematical writing is to keep the tone objective. While there may be lexical changes, the syntax and dialect primarily stays constant.

While there may be variations in pronunciation, it usage and grammar are the same. For example, an equation can be seen as a sentence. In $3 x+2=5$, " $3 x+2$ " can be seen as a compound subject, " $=$ " is the linking verb, and " 5 " is the predicate nominative. In pre-secondary level mathematics, all equations are comprised of the same way. The equal sign serves as a link between the signifier and the signified (O'Halloran, 2008). Therefore, the grammar stays constant throughout the subject.

When reading about mathematical writing methodologies, one can surmise that a mathematical sentence is primarily comprised of scripted words (Huang \& Normandia, 2007; MacGregor, 2005; Pugalee, 2005). As stated earlier, nominalizations represent complex concepts and processes in a simplified form. Then, nominalizations, even though they are nouns, can be representative of complete sentences. In order to understand what kind of sentence it represents, the writing analyst needs to know which nominalizations represent processes and which ones represents concepts. The two-column geometric proof (Figure 3) is a visual representation can be seen as being comprised of five to 10 sentences, depending on how the proof is read. 


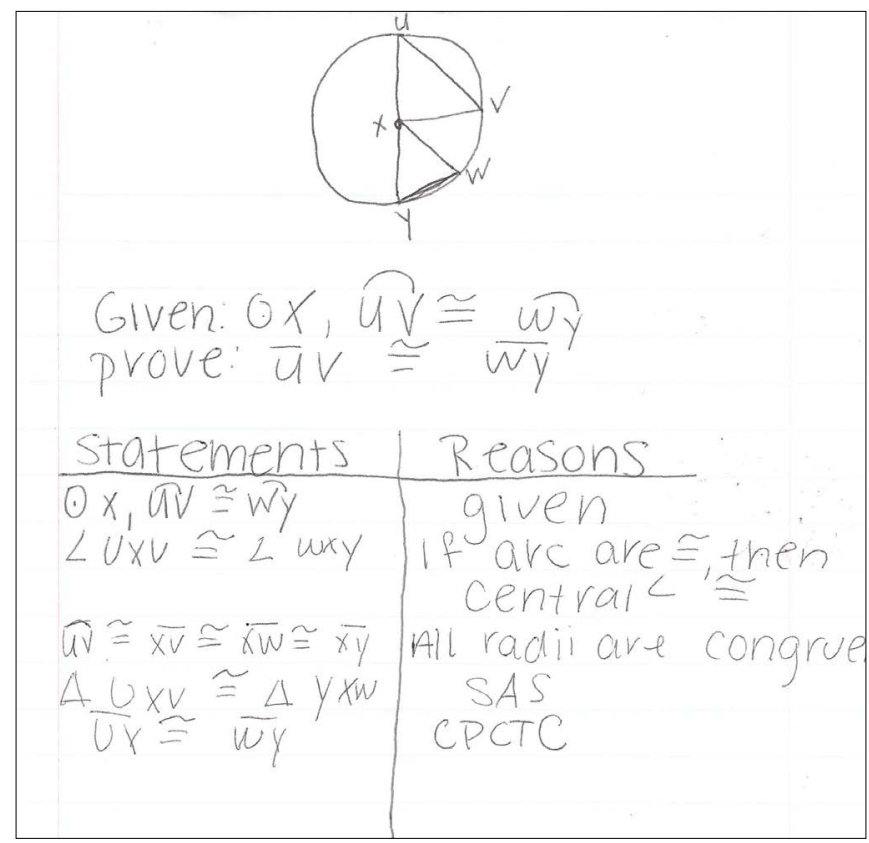

Figure 3: Example of a two-column geometric proof

The purpose of this study is to gain a better understanding of how pre-secondary students use mathematical writing elements in their routine instruction. Students are exposed to symbols, nominalizations, and images every day, from their textbooks and decorations/ posters on the classroom walls. As variables, each of these dependent variables will be used to code the data according to their frequencies and contextual uses.

\section{METHODOLOGY}

Prior to any data being collected, approval was granted from Chicago State University's Institutional Review Board and the District Superintendent.

\subsection{Setting}

LJH is a school that houses 7 th and 8 th grade students. There are 10 teachers in the Mathematics Department: five teachers in 7 th grade, and five teachers in 8th grade. All mathematics classes had between 20-30 students. Teachers had the freedom to organize the students' learning spaces. Of the 10 teachers, five teachers had the desks in rows (six rows of five desks each), three teachers put the desks into groups (six groups of five desks each), and two teachers had students sit at round tables (five students per table). One teacher had his desk at the back of the room, behind the students. Five teachers' desks were off to the side of the students, and four teachers had their desks at the front of the room. All classrooms had a laptop connected to a projector and white boards and/or chalkboards at the front of the room. In addition, all classrooms had mathematics related decorations on the walls, and these decorations had symbols, nominalizations, and/or images on them. 


\subsection{Subjects}

During school year 2017-2018, this school had 696 students in 7th and 8th grades (Illinois State Board of Education, 2018). Of the 696 students, 654 students submitted both the student assent form and the parent consent form (94\% return). Of these 654 students, 1257 th grade students and 130 8th grade students agreed to be part of this study (39\% return). In the United States, students of similar abilities are in the same class. For example, teachers can have a class of only students who have difficulty understanding and executing mathematical concepts and procedures, or they may have a class of students who are gifted in mathematics. Therefore, mathematics classes at this school are homogeneous with regards to student ability levels.

\subsection{Instruments}

The goal of this preliminary study was to understand the kinds of writing 7th grade and 8th grade students produced during their routine instruction. Teachers' routine instruction procedures did not change as a result of this study. Based on informal interviews, teachers stated that they chose bell-ringer activities or exit activities to submit as data. Bell-ringer activities are short, 5-10 minute exercises that help students recall information from prior lessons, in order to lead into and provide continuity to the current lesson (Kane, 2018). Teachers will give exit activities as a review of the day's lesson. Similar to the bell-ringers, exit activities are between 5-10 minutes, given at the end of the class period (Kane, 2018). One 8th grade teacher selected activities given for examination reviews. With all of the activities, none required grades from the teachers, and all were completed within the class period. No teacher gave copies of homework assignments or extracurricular mathematical activities as writing samples.

\subsection{Data Collection Process}

The first meeting was with the mathematics department (10 teachers). At this meeting, the teachers learned of the research project and their responsibilities. In addition, the teachers explained the school's mathematics curriculum, the general organization of each class, and the topics that are covered over the course of each quarter. After explaining the goals of this research project, they were given assent forms to read and sign. All 10 teachers signed the assent forms. At the end of the meeting, a date was set for the primary investigator $(\mathrm{PI})$ to visit the mathematics classes and to determine when to collect the student assent and parental consent forms.

To obtain student assent and parental consent, the PI visited every mathematics class over the course of one school day (8 hours). During these visits, she explained the study to the students and answered their questions. Also at this time, the PI conducted informal observations of the learning environment. These observations included the organization of the desks in relationship to the teacher's planning space, the decorations on the classroom walls, and the kinds of technology used in the classroom. Each classroom visit lasted 10 minutes.

Once student assent and parental consent forms were received, a list of students who agreed to be part of the study was given to the teachers. Each student was assigned a number, and the teachers were instructed to replace the students' names with the corresponding numbers. This method provided anonymity, because the PI did not personally know the students. When the teachers agreed to participate in this study, they also agreed to not penalize the students who chose not to be part of this study. The PI gave each teacher 
seven envelopes, one for each month between November and April. Over a six month period, teachers submitted copies of their students' work. For three months (December, January, February), not all of the 8th grade teachers submitted writing sample because they took class time to prepare their students for high school entrance examinations. As a result, 1,276 pieces of writing were collected. There were students who did not submit all six writing samples because they were absent from class. The PI reached her goal of obtaining writing samples, from the use of symbols only to the use of symbols, nominalizations, and images.

\subsection{Analysis Process}

These writing samples were analyzed through discourse analysis. Discourse analysis looks at how language is used in order to convey meaning (Seo, 2017). Gee (2015) stated that there are two kinds of discourse: Discourse (with an upper case "D") and discourse (with a lower case "d"). Discourse, with an upper case "D" focuses on not only what is written but also in what context, where it was written, the social interactions within the classroom, and the communication environment as a whole, while discourse, with a lower case " $d$ " focuses only on the words that are used in the communication (Gee, 2015). In educational research, discourse analysis often focuses on classroom talk, analyzing who says what, what is being said, and the interaction between the subjects, their context, and the topics. Discourse is determined semantically by what will be said, and pragmatically by how it is situated (van Dijk, 2008).

For the purposes of this discourse analysis, the focus is on the mathematical writing elements that the students used. There is an interaction between the student, the text, and the audience, and it is within this interaction where meaning is to be conveyed (Bahktin, 1981). In this case, meaning is determined by the students' abilities to convey their mathematical knowledge through their writings. Conveyed meaning is more than getting the mathematical problem solved correctly. It also includes procedural and conceptual explanations (NCTM, 2000). More commonly used in analyzing oral exchanges, discourse analysis (with a small "d") is between individuals or within classroom discussions. During these exchanges, non-verbal expressions are noted, and those notations are included with the textual data. For this study, the data is static because the focus is on what the students wrote, not their oral expressions during the writing process.

As stated earlier, the focus was on what the students wrote, not where, because the settings of these students are equivalent. The most fundamental coding method in discourse analysis is identifying the number of times and where a linguistic element occurs in the writing samples. For example, a researcher may want to know how often the word "an" is used, counting every occurrence of that word. Then, that same researcher will focus on where "an" is used, whether it is in a sentence, a figure or as a semantic unit. These mathematical writing samples were coded similarly, with the linguistic elements of symbols, nominalizations, and images. For each grade level, there were two levels of coding. First, I counted how many times each element was used. Second, I examined in what context the element was used. For example, symbols were used in all 1,276 mathematical writing samples. Out of the 708 writing samples from 7 th grade students, 119 writing samples had images, and these images were only used as an organization tool when solving geometric problems. The focus of these themes was to identify similarities and differences among the 7th grade students as a whole and the 8th grade students as a whole. 


\section{RESULTS}

The student writing samples were examined as two units. One unit is the 7 th grade students, and the second unit is the 8th grade students. It was necessary to examine the kinds of writing as a whole before examining it into parts.

For both grades, students wrote according to what was expected of them. Whether it was via oral directions and/or presentation of mathematical concepts and problems, all students answered the mathematical questions. Since there were no observations of teachers' interactions with their students, the focus of this study is on the written presentation of the mathematical problems, the static data. These presentations were in the form of a problem on the chalkboard (i.e. Solve for $x$ : $2 x+3=9$ ), an assignment in a mathematics textbook (i.e. On page 24 , complete problems 1,3 , and 5 ), or they were part of a worksheet. When students complete problems from the chalkboard and the textbooks, they do not write the question first and then solve the problem. Instead, students solve the problem on loose-leaf paper and give it to the teacher to grade (See Figure 4). Students assume that their teacher understands what they wrote. In another study, 7th grade students have stated that when they write mathematically for their mathematics teachers, they do not need to explain the mathematical processes in detail because as one student stated, "The math teacher already knows this stuff' (Seo, 2011).

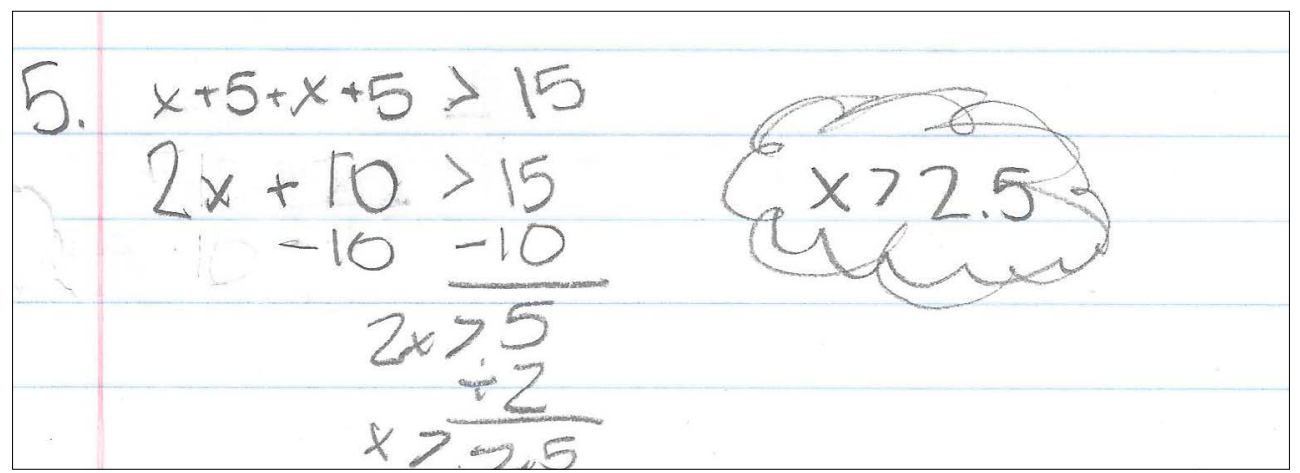

Figure 4: Seventh grade student's work on paper

On the surface, Figure 4 looks like a collage of symbols and logograms: numbers, addition sign, horizontal lines, and dots. However, as Lemke (1995) stated, mathematics is a highly condensed language, and only those who are familiar with the language can determine its meanings. Therefore, Figure 4 also shows how the 7 th grade students used numbers, letters, and logograms to express the mathematical meaning. The letter " $x$ " represented an unknown value, and the logogram " $>$ " represented the concept of one side of the equation is less than the other side of the equation.

\subsection{Seventh Grade Students}

Seventh grade students used symbols, nominalizations, and images in order to convey their mathematical knowledge. Writing samples from the 7th grade students contained symbols, nominalizations, and images. At the beginning of the year, students wrote symbols only. However, as the year progressed and the mathematical concepts became more difficult, the students learned to incorporate nominalizations and images in their mathematical writing. 
As previously stated, 7th grade students used images when solving geometric problems. Geometry is considered to be a more advanced level of mathematics, and it is taught towards the end of the second term. While there may be an expectation of the use of images, it is not necessarily required.

\subsubsection{Use of Symbols}

Writing samples collected at the beginning of the first term consisted of only symbols. For example, Figure 4 was obtained during the first data collection during the second month of the academic year. In Figure 4, the student used symbols and wrote mathematical sentences, changing the format yet keeping the same meaning (van Dyck \& Heefer, 2014). All students who submitted writing on loose-leaf paper had the same format and vertical organization. Through informal observations of the teachers' classrooms, all of the 7th grade teachers had posters and other decorations on the walls that exhibited this same organization.

\subsubsection{Use of Nominalizations}

Nominalizations are introduced as vocabulary words at the beginning of each unit. However, 7th grade students are not required to use these words in their mathematical writing assignments. Referring to Figure 4 again, the student is expressing Additive Property in the calculations. While the student does not write the words "Additive Property," the calculations illustrate this nominalization.

\subsubsection{Use of Images}

As stated earlier, images are static and are often used as an organization tool (O'Halloran, 2008). Images are content specific. In pre-secondary level mathematics, they are used when solving geometric problems. Geometry is a topic that is covered later in the academic year. At LJH, it is at the beginning of the second term. For example, the writing sample in Figure 5, which is representative of the 119 uses of images, was collected in the middle of the school year at the beginning of the second term. Thus, it is not surprising that this student used symbols and images. The symbols are the numerals and mathematical notation, and the image is used as a device to organize the student's mathematical thinking:

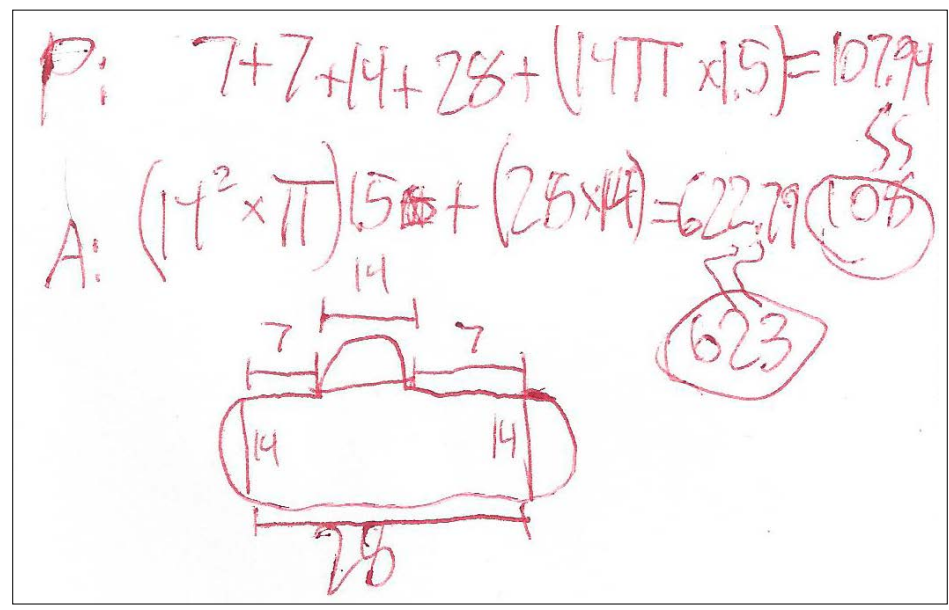

Figure 5: Seventh grade student's use of symbols and images 
"P" designates the perimeter, and "A" designates the area. In order for the student to keep the values in place, this person used this image of the rectangle and half-circles as an organization tool. The student assigned numbers to the corresponding parts of the image. Once the values have been visualized, it is easier for the student to determine the perimeter and area for this problem.

An example of a 7th grade student using symbols, nominalization, and images can be seen in Figure 6. This example was collected towards the end of the school year. In this case, the student used numerals, mathematical notation, nominalization, and a triangle (image). In this case, the student wrote "110" at the bottom left angle of the triangle, and "25" at the bottom right angle of the triangle. The nominalization "angle" designates what the student is trying to explain, and the symbolic notation are in the form of numbers and degree notation (i.e. $110^{\circ}$ ). The image, as a static entity, is used to illustrate and clarify what the student wrote.

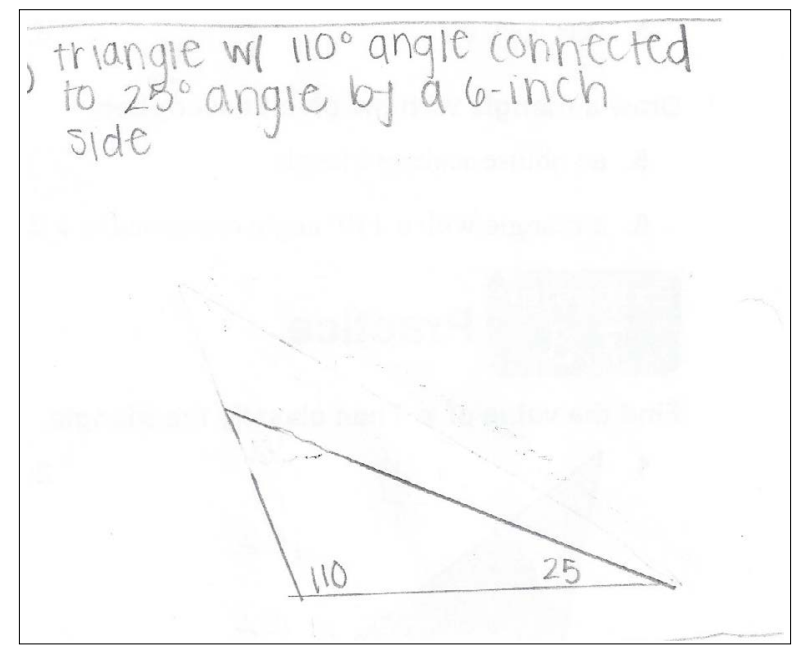

Figure 6: Seventh grade student using symbols, nominalization, and image

\subsubsection{Use of Graphic Organizers}

Graphic organizers are learning tools for students to organize their mathematical thoughts. Teachers will give specific directions when using them (Kane, 2018). Therefore, it is not surprising that the 7th grade students conformed their writing to the expectations of the graphic organizer because they are, in a sense, conditioned to do so. All of the answers are written within the organization's boundaries. In addition, because the worksheet specifically asked for symbolic writing, the student complied (see Figure 7). 


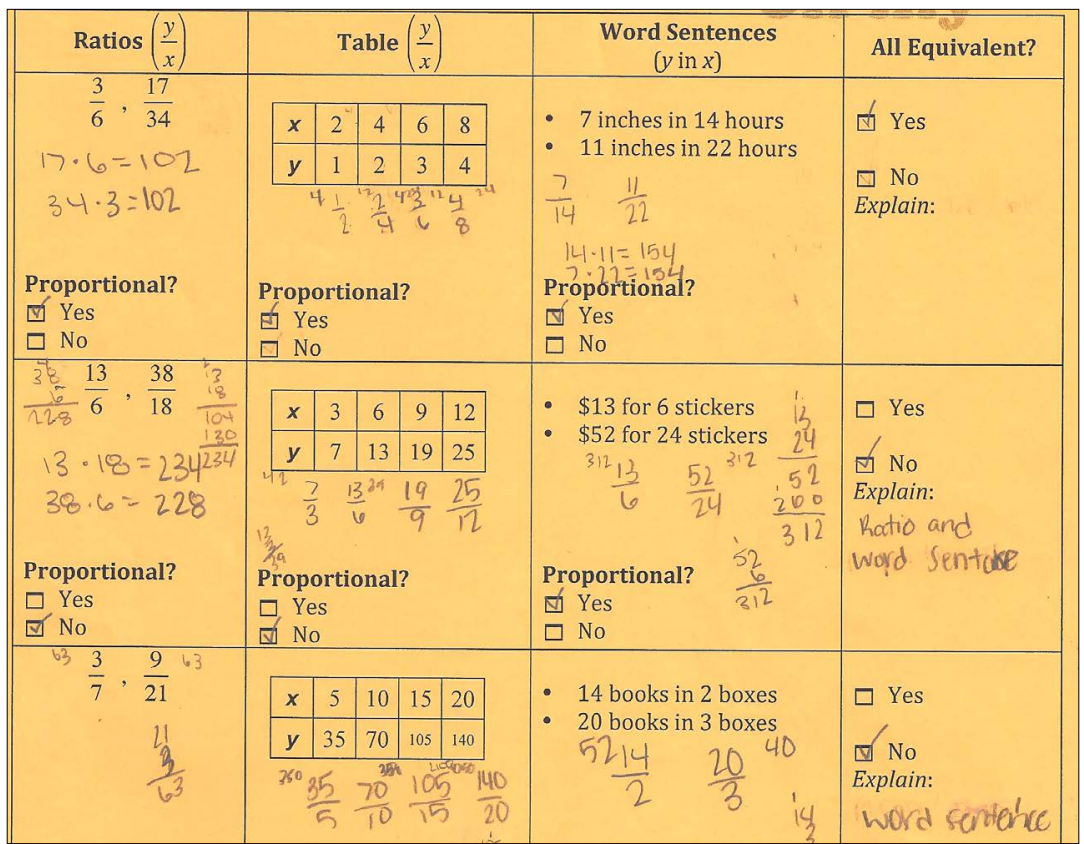

Figure 7: Seventh grade student's work with a graphic organizer

Out of 708 writing samples from 7 th grade students, these figures are representative of what the group as a whole submitted. In terms of the research question, 7 th grade students use all of the mathematical writing elements. However, based on when the writing sample was collected, it seems that the use of images and nominalizations are more advanced elements for them to employ. Symbols are used throughout the six-month period, but images were used during their geometry unit, and nominalizations were introduced towards the end of their geometry unit.

\subsection{Eighth grade Students}

At LJH, all 8th grade students take pre-algebra. However, the advanced students will complete the pre-algebra curriculum in one term and start an algebraic curriculum in the second term of the academic year. Unlike the 7th grade students who are gradually introduced to the uses of nominalizations and images, 8th grade students will incorporate symbols, images, and nominalizations in their routine classroom work from the beginning of the year. While 7 th grade students are introduced to geometric concepts at the beginning of the second term, geometry is one of the first lessons in the 8th grade curriculum.

The 8th grade teachers preferred to use graphic organizers and worksheets out of a workbook that corresponded with their textbook. Similar to the 7 th grade students, 8 th grade students wrote within the given organization of the learning tool, and they used symbols, nominalizations, and images simultaneously, when the learning tool asked for that specificity. As seen in Figure 8, this 8th grade student used specific mathematical writing elements in the appropriate sections. 
B. Write a function that relates your friend's earnings to the number of hours worked.

Friend's Equation: $\quad y=x+9$

C. Graph both functions on the graph below. Be sure to label your graph and the functions.

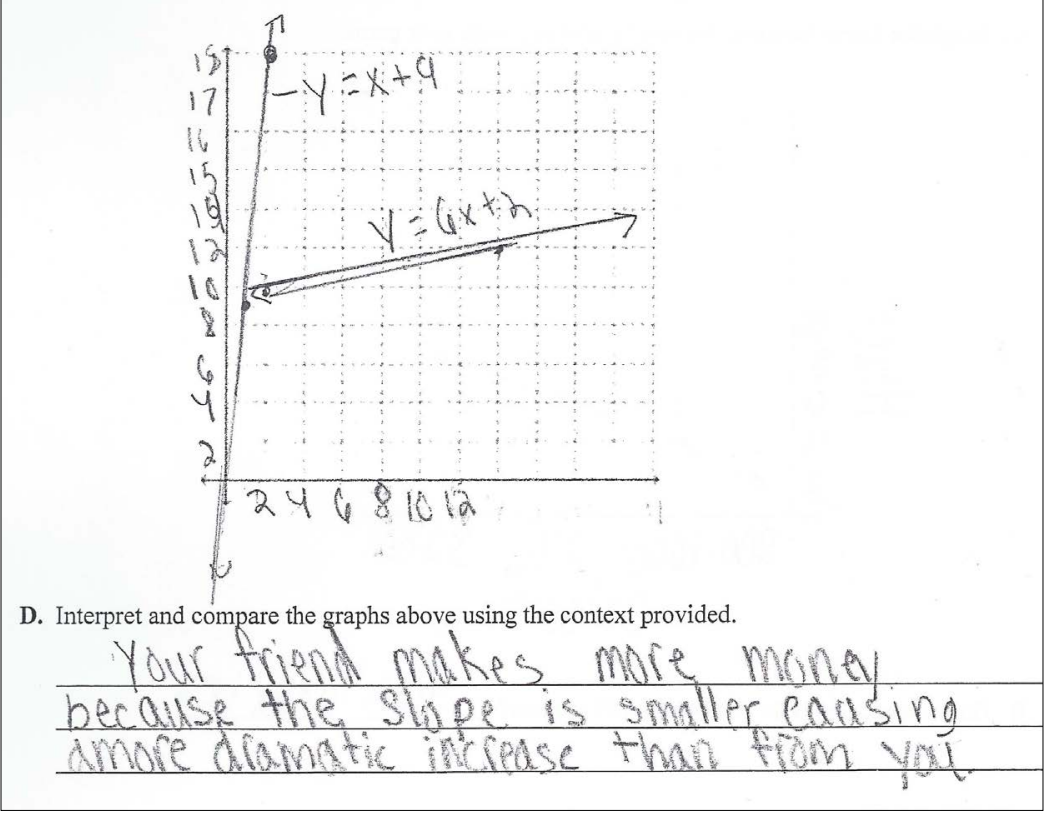

Figure 8: Eighth grade student example using symbols, nominalizations, and images

While Figure 8 is not technically a graphic organizer like Figure 7, this worksheet asks students to use the mathematical writing elements in specific places. For example, question $B$ asks the student to write a related function; functions are often written using symbols, specifically numbers and logograms. Question C provides a template of a graph, which signals to the student that an image needs to be drawn in its place. Instead of using the image as an organizing device, the graph is used as an instrument to clarify the symbolic writing. Finally, question D asks for an interpretation of the mathematical symbols and image. In the explanation, the students uses the nominalization "slope" to designate the quality of the incline of the line.

This negotiation of mathematical elements was commonly seen in the 8th grade Algebra classes. These advanced students have the mathematical knowledge and acumen to use all of the mathematical elements to communicate and convey mathematical meanings.

The 8th grade students submitted 568 writing samples. Of these writing samples, 201 writing samples only contained symbols. Figure 9 is an example of an 8th grade student only using symbols. What is important to note is that the directives stated "Solve using the best method:" and the student chose to use only symbols to show the best method of solving the problem. Eighth grade students, as a whole, used only symbols with the simple directive "Solve." 


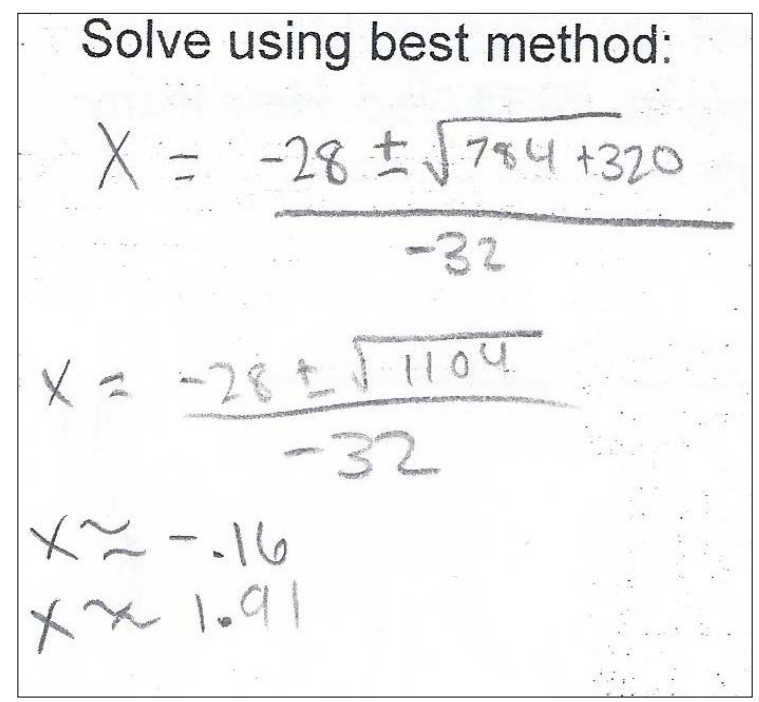

Figure 9: Eighth Grade Student Using only Symbols

Of the 8th grade writing samples, 185 writing samples had two of the three elements: symbols and images. Similar to the 7 th grade students, 8 th grade students used images as an organizational tool in geometric problems. However, unlike the 7 th grade students, 8 th grade students solve geometric problems during the first term of the school year (See Figure 10).

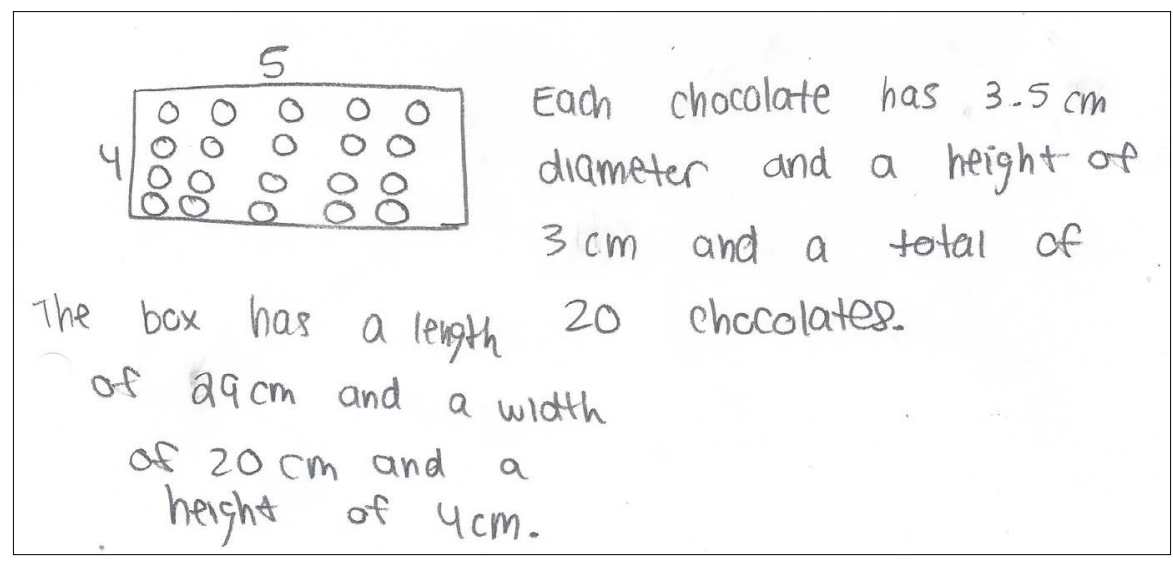

Figure 10: Eighth Grade Student Using an Image as an Organizational Tool

Finally, 182 writing samples from the 8th grade students contained all three mathematical writing elements: symbols, nominalizations, and images (See Figure 8). While symbols were used when solving all of the mathematical problems, nominalizations were used only when directed as in Figure 8.

\section{DISCUSSION}

In 2009, Seo learned that audience theory could be applied to mathematical writing. Audience theory states that writers will adapt their writing style and language according to whom they 
are writing. Even when writers can have the same content, the way this content is expressed differs (Ede \& Lunsford, 1984). In that study, 10th grade student wrote mathematically in mathematics and English classes. Results showed that students in the English class wrote scripted words to the English teacher while the same students used only symbols and images when communicating to their mathematics teachers. In other words, the students adapted their writing styles according to their audiences (Seo, 2009). With these analyzed writing samples in this study, students conformed their writing according to the form that was presented to them. This characteristic is clearly seen in Figures 7 and 8 . In Figures 7 and 8 , students wrote all of their answers within the boxes that were given to them. These students did not have stray writing outside of the boxes. The student used symbols (equations), nominalizations (words) or images (graph) only in the sections that asked for it.

The data also showed that mathematical writing is task dependent. As seen in Figures 7 and 8, whatever elements students used depended on the mathematical activity. When instructed to simplify and solve equations, students used exclusively symbols, conveying their mathematical ideas through as Pimm (1995) would say, numerical sentences. Students also used scripted words and the appropriate nominalizations and/or images to express their ideas as seen in Figures 6 and 8, which shows that students are able to manipulate more than one mathematical writing element in order to convey their mathematical meanings. Images were also used as a means of organizing and/or clarifying the mathematical information in a way that was easier for the student to understand (See Figures 5, 6, and 8).

All of the mathematical elements are equitably used based on the mathematical task. As seen in Figure 8, there were specific places to use the appropriate mathematical writing element. For instance, when the student is asked to draw a graph, space is made on the worksheet for this image. Mathematical writing is used to convey mathematical ideas, and all of the students completed that task using mathematical writing. However, in order to understand those ideas, it is necessary for the reader, who can be a fellow student or teacher, to comprehend what Lemke (1995) would identify as highly condensed language. Individuals who understand the condensed language are also more likely to be able to manipulate it. Unlike the 7th grade students, 8th grade students used multiple mathematics writing elements earlier in the school year. This difference in performance would make sense because 8 th grade students have more mathematical knowledge than the 7 th grade students. With more knowledge comes better reading and writing of mathematical language. As individual entities or as a group, the elements can convey mathematical meaning. However, when more than one element is used in combination or all three at the same time, they work to convey the overall mathematical meaning (See Figure 8 ) for a given mathematical problem.

\section{CONCLUSION}

This preliminary analysis provided a generality of the kinds of mathematical writing 7 th grade and 8th grade students produced. Both groups of students employed audience theory in their mathematical writing assignments, and both groups used symbols, nominalizations, and images when asked by the teacher. Also, they conformed their writing based on the task that was asked of them to complete according to the perceived expectations of their teachers. This information is important to know because it shows that if teachers want their students to use specific mathematical writing elements, then these teachers need to pose mathematical problems that require their students to use all of the elements in their 
mathematical communication. Additional analysis is necessary in order to understand if this conformity is only seen at the surface level or if it exists at the linguistic level as well.

\section{REFERENCES}

Bakhtin, MM 1981. The dialogic imagination. Austin, TX: University of Texas Press.

Baxter, JA, Woodward, J, \& Olson, D 2005. Writing in mathematics: An alternative form of communication for academically low-achieving students. Learning Disabilities Research \& Practice, 20: 119-135. https://doi.org/10.1111/j.1540-5826.2005.00127.x

Brozo, WG \& Crain, S 2018. Writing in math: A disciplinary literacy approach. The Clearing House: A Journal of Educational Strategies, Issues, and Ideas, 91: 7-13. https://doi.org/10.10 $80 / 00098655.2017 .1342435$

Bruun, F, Diaz, JM, \& Dykes, J 2015. The language of mathematics. Teaching Children Mathematics, 21: 530-536. https://doi.org/10.5951/teacchilmath.21.9.0530

Colonese, MW, Amspaugh, CM, LeMay, S, Evans, K \& Field, K 2018. Writing in the disciplines: How math fits the equation. The Reading Teacher, 72: 379-387. https://doi.org/10.1002/trtr.1733

Ede, L \& Lunsford, A 1984. Audience addressed/audience invokes; The role of audience in composition theory and pedagogy. College, Composition and Communication, 33: 155-171. https://doi.org/10.2307/358093

Ernest, P 2008a. Towards a mathematical text (Part 1). For the Learning of Mathematics, 28: 2-8.

Ernest, P 2008b. Towards a mathematical text (Part 2). For the Learning of Mathematics, 28: 39-47. https://doi.org/10.1007/978-3-642-00742-2_4

Gee, JP 2015. Social linguistics and literacies. UK: Taylor \& Francis. https://doi. org/10.4324/9781315722511

Hammill, L 2010. The interplay of text, symbols, and graphics in mathematics education. Transformative Dialogues: Teaching \& Learning eJournal, 3. Retrieved from www.kpu.ca/td/ past-issues/3-3

Harris, R 1995. Signs of writing. NY: Routledge.

Huang, J \& Normandia, B 2007. Learning the language of mathematics: A study of student writing. International Journal of Applied Linguistics, 17: 294-318. https://doi. org/10.1111/j.1473-4192.2007.00173.x

Illinois State Board of Education 2018. Illinois school report card. Retrieved from www.isbe.net Jao, L \& Hall, J. 2018. The important things about writing in a secondary mathematics classes. Australian Mathematics Teacher, 74(1), 13-19.

Kane, S 2018. Literacy and learning in the content areas. NY: Routledge. https://doi. org/10.4324/9781351206914

Kennemeyer, L, Jenkin, A, van Zyl, M \& Scheffler, C. 2014. Grade 10 mathematics: Everything maths. Pretoria, Guateng Province, SA: Department of Basic Education.

Lemke, JL 1995. Textual politics. London, UK: Taylor \& Francis. 
MacGregor, M 2005. Reading and writing in mathematics. In J Brickmore-Brand (ed) Language in Mathematics. Portsmouth, NH: Heinemann, 100-108.

Martin, CL 2015. Writing as a tool to demonstrate mathematical understanding. School Science and Mathematics Journal, 115: 302-313. https://doi.org/10.1111/ssm.12131

Mclntosh, ME \& Draper, RJ 2001. Using learning logs in mathematics: Writing to learn. Mathematics Teacher, 94: 554-557.

Morgan, C 1998. Writing mathematically: The discourse of investigation. London, UK: Falmer Press.

National Council of Teachers of Mathematics [NCTM] 2000. Principles and standards for school mathematics. Reston, VA: Author.

O' Halloran, KL 2008. Mathematical discourse: Language, symbolism, and visual images. NY: Continuum.

Pimm, D. 1995. Symbols and meanings in school mathematics. London: Routledge.

Pugalee, D 2001. Writing, mathematics, and metacognition: Looking for connections through students' work in mathematical problem solving. School Science and Mathematics Journal, 101: 236-245. https://doi.org/10.1111/j.1949-8594.2001.tb18026.x

Pugalee, D 2005. Writing to develop mathematical understanding. Norwood, MA: ChristopherGordon Publishers.

Rotman, B 2000. Mathematics as sign. Stanford, CA: Stanford University Press.

Santos, C \& Semana, S 2014. Developing mathematics written communication through expository writing supported by assessment strategies. doi: 10.1007/s10649-014-9557-z

Seo, B-I 2009. Understanding the effects of audience on mathematical writing. School Science \& Mathematics, 109: 116-127. https://doi.org/10.1111/j.1949-8594.2009.tb17944.x

Seo, B-I 2011. Working in tandem: Understanding mathematical writing in 7th grade ELA classes. Illinois English Bulletin, 98: 31-50.

Seo, B-I 2015. Mathematical writing: What it is and how do we teach it. Journal of Humanistic Mathematics, 5: 133-145. https://doi.org/10.5642/jhummath.201502.12

Seo, B-I 2017. Written discourse analysis: Looking at adolescent mathematical writing. SAGE Research Methods Cases. London, UK: SAGE Publications Ltd. doi: http://dx.doi. org/10.4135/9781473997042

Sfard, A. 2000. Symbolizing mathematical reality into being--Or how mathematical discourse and mathematical objects create each other. In P Cobb, E Yackel, \& K McClain (eds.) Symbolizing and Communication in Mathematics Classrooms. Mahwah, NJ: Lawrence Erlbaum Publishers, 37-98.

van Dijk, TA2008. Critical discourse analysis and nominalization: Problem or pseudo-problem? Discourse \& Society, 19: 821-828. https://doi.org/10.1177/0957926508095897

van Dyck, M \& Heefer, A 2014. Script and symbolic writing in mathematics and natural philosophy. Foundations of Science, 19: 1-10. https://doi.org/10.1007/s10699-012-9310-y

Williams, KM 2003. Writing about the problem-solving process to improve problem-solving performance. Mathematics Teacher, 96: 185-187. 